\title{
Potential Biomarkers for Intellectual Disability: A Gipsy Family Study
}

Aureli $A^{1}$, Del Beato $T^{1}$, Sebastiani $\mathbf{P}^{1}$, Di Rocco $\mathbf{M}^{1}$, Marimpietri $A E^{2}$, Graziani $A^{2}$, Sechi $E^{2}$ and Di Loreto $\mathbf{S}^{1^{*}}$

${ }^{1}$ Institute of Translational Pharmacology, National Council of Research, L'Aquila, Italy

${ }^{2}$ Childhood and Adolescence Neuropsychiatric Clinic, University of L'Aquila, ASL n. 4, L'Aquila, Italy

*Corresponding author: Silvia Di Loreto, Institute of Translational Pharmacology, National Council of Research, L'Aquila, Italy, Tel: +39 0862318843 ; Fax: +39 0862 320750; E-mail: silvia.diloreto@cnr.it

Rec Date: September 15, 2014, Acc Date: November 13, 2014, Pub Date: November 18, 2014

Copyright: (C) 2014, Aureli A, et al. This is an open-access article distributed under the terms of the Creative Commons Attribution License, which permits unrestricted use, distribution, and reproduction in any medium, provided the original author and source are credited.

\begin{abstract}
Intellectual disability (ID) is frequently due to the synergic action of environmental and genetic factors. Here we describe the particular case of three Gipsy Italian siblings, fifteen, twelve and eleven years old, with ID. Genetic analysis stated that the parents are not consanguineous, and no human leukocyte antigen (HLA) alleles related to autism and/or other neurological disorders are present in the 3 ID patients. Instead, a positive association of ID with brain derived neurotrophic factor (BDNF) (Val66Met and C270T), IL6 (-174) and interleukin 1receptor antagonist (IL1RA) mspa 11100 polymorphisms was demonstrated in these three ID patients. Moreover, serum levels of interleukin 1beta (IL1 $\beta$ ), interleukin 6 (IL6) were significantly different between the three patients and controls.
\end{abstract}

Keywords: Intellectual disability; Polymorphism; Cytokine; HLA; Neurotrophic factor

\section{Introduction}

Several genes are involved in ID etiology but the mechanisms by which these candidates regulate cognitive function remain poorly understood [1,2]. Cytokines play a central role in CNS functions and, some of them such as IL-1beta and IL- 6 have been associated with cognitive decline and dementia $[3,4]$ and are released during neuronal activity, playing a key role in regulating the strength of synaptic $[5,6]$.

Peripheral expression of cytokines can influence both in pathological and physiological conditions, the hippocampus-related memory and synaptic plasticity [7-9] and there is growing evidence that single nucleotide polymorphisms (SNPs) regulate theirs expression [10,11]. Several polymorphisms of BDNF gene have been described and in our previous study a positive association between ID and two BDNF SNPs was demonstrated (Val66Met and C270T) [12]. Current research increasingly also demonstrates a role of the HLA proteins in the functional interactions of neural cells, in CNS development [13], and even in neurological disorders [14]. The phenylketonuria (PKU), a defect in the hepatic enzyme phenylalanine hydroxylase $(\mathrm{PAH})$, is an inherited disorder that induces delayed mental and social skills. A higher incidence of PKU was demonstrated in Gypsies than in other populations [15], and two missense mutations have been identified in the PAH gene of an Italian PKU patient [16].

Herein, we report the particular case of three Gipsy ID siblings in which functional cytokine gene polymorphisms, serum levels of cytokines, HLA class I and II allele polymorphisms, BDNF gene polymorphisms and two PAH missense mutations have been studied.

\section{Case Report}

Three children belonging to a Gipsy family living in the area of the coast of the Adriatic Sea were enrolled at the Department of Neuropsychiatric Disorders of the Civil Hospital of L'Aquila, Italy (Figure 1A).

\section{Patient 1}

The first patient is a female born in 1999 without complications after a normal pregnancy. From birth, her psychomotor development was delayed, and included feeding problems. She was able to walk at the age of 18 months. At 5 years old she spoke only a few words and started intensive linguistic training. A severe intellectual disability was diagnosed (IQ 35). She is described as an easily irascible although quite sociable child.

\section{Patient 2}

The other female, born in 2002 after an uneventful pregnancy, developed critical anaemia after the birth and received blood transfusions. She began walking at 15 months old and a delay in language development and in the control of the sphincters was reported. Severe intellectual disability (IQ 34 ) was noticed early on. Some spread electric anomalies, particularly in the frontal lobe area, were observed by her electroencephalogram. She is shy and unable to integrate with peers.

\section{Patient 3}

The younger affected brother was born in 2003 by caesarean section. The same psychomotor development pattern seen in his affected sisters was present. His speech was delayed and he started to speak at 3 years old. A mild intellectual disability was diagnosed (IQ 59). He is short-tempered and does not socialize easily.

According to Diagnostic and Statistical Manual of Mental Disorders- IV Edition (DSM-IV) criteria, to access ID diagnosis Wechsler Intelligence Scale for Children-III (WISC-III), a standardized test of intellectual aptitude for children between ages 6 and 16 years, and the Vineland Adaptive Behaviour Scales (VABS) were administrated. The WISC-III subscales are used to generate four composite scores: verbal comprehension, perceptual reasoning, working memory, and processing speed. The VABS is a widely used tool for assessing an individual's ability to care for one's self personally and socially. The Child Behaviour CheckList (CBCL), a parent-report 
questionnaire to detect emotional and behavioural problems in children and adolescents and the Conners' Continuous Performance Test (C-CPT), which measures and evaluates a child's attention span and ability to maintain focus on a task, were used to further support conclusions and to evaluate general intellectual development (Figure 1B).

A

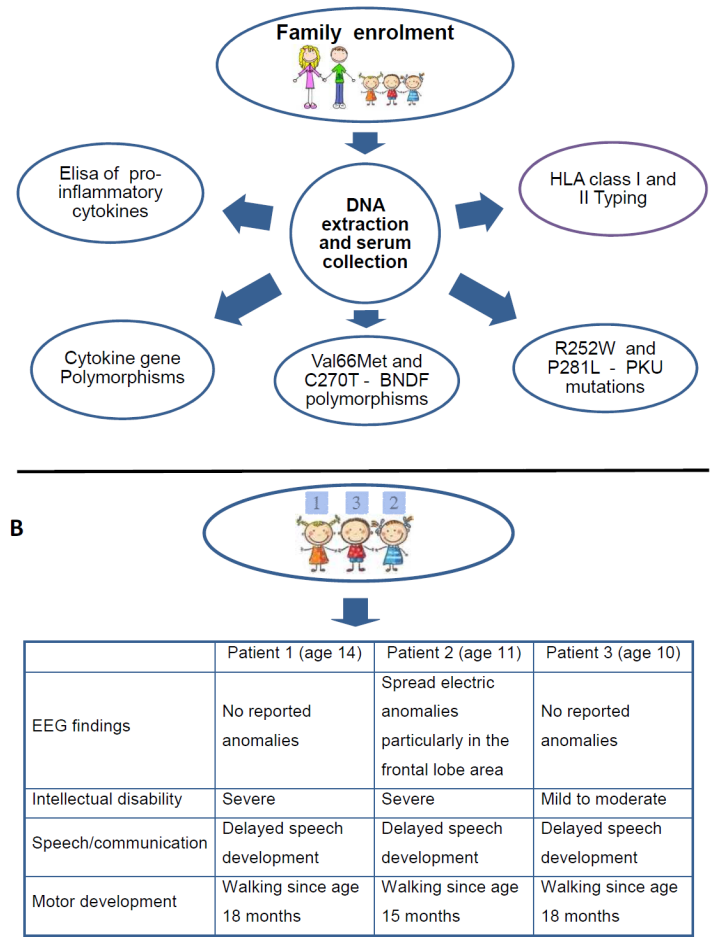

Figure 1: Side A represents a diagram of experimental steps. Side B summarizes results of clinician investigations carried out in each child.

Controls for cytokines and BDNF polymorphisms pertain to a larger case-control group studied previously [12]. Nine healthy children age and sex matched with the siblings were selected as controls for cytokine levels (Figure 2B).

Venous blood was drawn from three siblings and their parents.

Genomic DNA was extracted using QIAamp DNA blood Midi Kit.

Cytokine gene polymorphisms were investigated in patients and controls using the Pel-Freez Cytokine Genotyping Kit [17].

All 3 ID Gipsy siblings presented the specific IL-6 (-174) G/C and the IL-1RA mspa11100 T/T genotypes both associated with an increased risk to develop ID [17] and the IL6 GG/CA predisposing aplotype [17].

HLA class I (A, B, and Cw) and class II (DRB1) sequence-based typing (SBT) [18] investigation showed that: a) parents of the 3 ID children are not consanguineous; $b$ ) the father has some peculiar HLA alleles (HLA-DRB1 ${ }^{*} 15: 02$, HLA-B ${ }^{\star} 52: 01$ and $\mathrm{Cw}^{*} 12: 02$ ) of Hungarian and Spanish Gypsies [19]; and c) no HLA alleles related to autism and/or other neurological disorders are present in the 3 ID patients
(Figure 2A). The SBT of BDNF [12] and PAH [16] SNPs showed that the three ID patients had the G/A genotype for BDNF-Val66Met and the $\mathrm{C} / \mathrm{C}$ genotype for BDNF-C270T but the normal C/C genotype for each of two missense mutations of $\mathrm{PAH}$.

Using the Human Inflammatory Cytokines Multi-Analyte ELISArray $^{\text {ma }}$ Kits (Qiagen), we demonstrated that IL6 and IL1 $\beta$ levels were significantly higher in ID Gipsy siblings than in controls (Figure 2B). No significant differences were displayed for the IL1RA neither for the other cytokines.

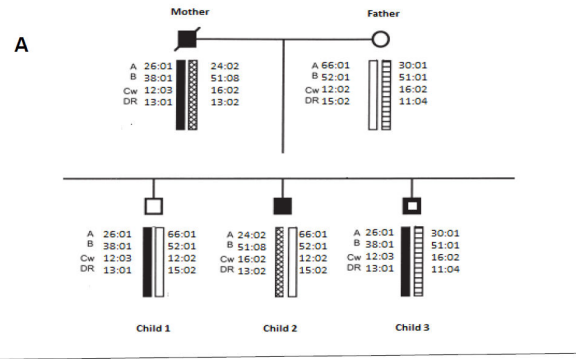

B

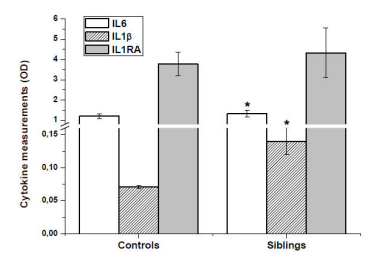

Figure 2: HLA typing of the family and the inheritance of haplotype (A). Study of the HLA class I (A, B, and Cw) and class II (DRB1) gene polymorphisms was conducted at high resolution by sequence-based typing (SBT) assay using commercial class I and class II sequencing kits (Abbott Molecular AlleleSEQR HLA-SBT ). Sequencing was carried out on a 3130 Genetic Analyzer (Applied Biosystems). Assign SBT v 3.5+ software (Conexio Genomics, Applecross, Australia) used the allele assignment to detect the heterozygous positions within each electropherogram and assess the typing on the basis of an alignment of the processed sequence with an updated HLA sequence library. (B) Measurements of cytokine levels were carried out using the Multi-Analyte Profiler ELISArray Kit (Qiagen) according to the manufacturer's instructions. Three fourteen and three twelve years old females and three eleven years old males were selected as controls. Results are reported as absorbances at $450 \mathrm{~nm}$. Statistical analyses were performed using the statistical package for the social sciences (SPSS) version 11.0 (SPSS, Tokyo, Japan). A Mann-Whitney test for non-parametric data was used to compare media. ${ }^{*} p=0.011$ for IL6; ${ }^{*} p=0.035$ for IL1 $\beta$.

\section{Discussion}

In this case report we show a set of genetic characteristics associated with ID in sibs that have not shown evident hereditary problems linked to cognitive impairment. Moreover, the anamnestic investigations did not highlight the relevant problems in the history of the family. 
Page 3 of 3

The involvement of pro-inflammatory cytokines, has been amply demonstrated in neurological conditions [20-22] since they alter the activity of the central nervous system and neuroendocrine, increase the release of neurotransmitters, induce the activation of immediate early genes in the brain and change the basic behaviours [23], as well as the functions of learning and memory [24,25]. In the three ID Gypsy patients, we found the entire predisposing genetic cytokine profile previously observed in a larger case-control study [17] and a significant higher level of IL1 $\beta$ and IL6 in the three ID patients.

Confirming previous reports $[12,26]$, we observed the positive association between both Val/Met and C270T BDNF SNPs and ID. In addition, the children not showed any HLA class I (A2) and class II (DR4) alleles related to autism and/or to cognitive impairment [27,28]. On the contrary the HLA investigations allowed us to trace the Gipsy origin of the family and to exclude the parental consanguinity.

Last but not least, considering the gipsy origin of the father, we investigated two most prevalent mutations of $\mathrm{PAH}$ associated to PKU, showing the normal homozygous $\mathrm{C} / \mathrm{C}$ genotype for both mutations in all the three sibs.

The case reported here summarizes results previously published by us and by others [12-26] and demonstrates the possible clinical relevance of immune and neurotrophic factor polymorphisms in cognitive impairment. This knowledge could represent a useful diagnostic tool to clinicians and could help to assess the risk to a person carrying a particular allele or haplotype of developing a neurological disease and thus contribute to a better understanding of its pathogenesis.

\section{Acknowledgments}

We thank the children and their family for participating in this study. This study was supported by grants from the Carispaq Foundation of L'Aquila, Italy.

\section{References}

1. Gécz J, Shoubridge C, Corbett M (2009) The genetic landscape of intellectual disability arising from chromosome X. Trends Genet 25: 308-316.

2. Kaufman L, Ayub M, Vincent JB (2010) The genetic basis of nonsyndromic intellectual disability: a review. J Neurodev Disord 2: 182-209.

3. Gonzalez P, Machado I, Vilcaes A, Caruso C, Roth GA, et al. (2013) Molecular mechanisms involved in interleukin 1-beta (IL-1ß)-induced memory impairment. Modulation by alpha-melanocyte-stimulating hormone (a-MSH). Brain Behav Immun 34: 141-150.

4. Economos A, Wright CB, Moon YP, Rundek T, Rabbani L, et al. (2013) Interleukin 6 plasma concentration associates with cognitive decline: the northern Manhattan study. Neuroepidemiology 40: 253-259.

5. Marin I, Kipnis J (2013) Learning, memory and the immune system. Learn Mem 20: 601-606.

6. McAfoose J, Baune BT (2009) Evidence for a cytokine model of cognitive function. Neurosci Biobehav Rev 33: 355-366.

7. Barrientos RM, Higgins EA, Biedenkapp JC, Sprunger DB, WrightHardesty KJ, et al. (2006) Peripheral infection and aging interact to impair hippocampal memory consolidation. Neurobiol Aging 27: 723-732.

8. de Maat MP, Bladbjerg EM, Hjelmborg Jv, Bathum L, Jespersen J, et al. (2004) Genetic influence on inflammation variables in the elderly. Arterioscler Thromb Vasc Biol 24: 2168-2173.
9. Dik MG, Jonker C, Hack CE, Smit JH, Comijs HC, et al. (2005) Serum inflammatory proteins and cognitive decline in older persons. Neurology 64: 1371-1377.

10. Bidwell J, Keen L, Gallagher G, Kimberly R, Huizinga T, et al. (1999) Cytokine gene polymorphism in human disease: on-line databases. Review. Genes and Immunity 1(1): 3-19.

11. Ollier WE (2004) Cytokine genes and disease susceptibility. Cytokine 28: 174-178.

12. Aureli A, Del Beato T, Sebastiani P, Marimpietri A, Melillo CV, et al. (2010) Attention-deficit hyperactivity disorder and intellectual disability: a study of association with brain-derived neurotrophic factor gene polymorphisms. Int J Immunopathol Pharmacol 23: 873-880.

13. Xiao BG, Link H (1998) Immune regulation within the central nervous system. J Neurol Sci 157: 1-12.

14. Bailey SL, Carpentier PA, McMahon EJ, Begolka WS, Miller SD (2006) Innate and adaptive immune responses of the central nervous system. Crit Rev Immunol 26: 149-188.

15. Kalanin J, Takarada Y, Kagawa S, Yamashita K, Ohtsuka N, et al. (1994) Gypsy phenylketonuria: a point mutation of the phenylalanine hydroxylase gene in Gypsy families from Slovakia. Am J Med Genet 49: 235-239.

16. Okano Y, Wang T, Eisensmith RC, Longhi R, Riva E, et al. (1991) Phenylketonuria missense mutations in the Mediterranean. Genomics 9: 96-103.

17. Aureli A, Sebastiani P, Del Beato T, Marimpietri AE, Graziani A, et al. (2014) Involvement of IL-6 and IL-1 receptor antagonist on intellectual disability. Immunol Lett.

18. Aureli A, Sebastiani P, Del Beato T, Marimpietri A, Melillo V, et al. (2008) Investigation on the possible relationship existing between the HLA-DR gene and attention deficit hyperactivity disorder and/or mental retardation. Int J Immunopathol Pharmacol 21: 985-991.

19. Ramal LM, de Pablo R, Guadix MJ, Sánchez J, Garrido A, et al. (2001) HLA class II allele distribution in the Gypsy community of Andalusia, southern Spain. Tissue Antigens 57: 138-143.

20. Cojocaru IM, Cojocaru M, Miu G, Sapira V (2011) Study of interleukin-6 production in Alzheimer's disease. Rom J Intern Med 49: 55-58.

21. Lynch MA (2014) Neuroinflammatory changes negatively impact on LTP: A focus on IL-1 $1 \hat{\mathrm{I}}^{2}$ Brain Res.

22. Forlenza OV, Diniz BS, Talib LL, Mendonça VA, Ojopi EB, et al. (2009) Increased serum IL-1beta level in Alzheimer's disease and mild cognitive impairment. Dement Geriatr Cogn Disord 28: 507-512.

23. Wilson CJ, Finch CE, Cohen HJ (2002) Cytokines and cognition--the case for a head-to-toe inflammatory paradigm. J Am Geriatr Soc 50: 2041-2056.

24. Hayley S, Poulter MO, Merali Z, Anisman H (2005) The pathogenesis of clinical depression: stressor- and cytokine-induced alterations of neuroplasticity. Neuroscience 135: 659-678.

25. Goshen I, Kreisel T, Ben-Menachem-Zidon O, Licht T, Weidenfeld J, et al. (2008) Yirmiya R. Brain interleukin-1 mediates chronic stress-induced depression in mice via adrenocortical activation and hippocampal neurogenesis suppression. Mol Psychiatry 13: 717-728.

26. Hariri AR, Goldberg TE, Mattay VS, Kolachana BS, Callicott JH, et al. (2003) Brain-derived neurotrophic factor val66met polymorphism affects human memory-related hippocampal activity and predicts memory performance. J Neurosci 23: 6690-6694.

27. Torres AR, Sweeten TL, Cutler A, Bedke BJ, Fillmore M, et al. (2006) The association and linkage of the HLA-A2 class I allele with autism. Hum Immunol 67: 346-351.

28. Lee LC, Zachary AA, Leffell MS, Newschaffer CJ, Matteson KJ, et al. (2006) HLA-DR4 in families with autism. Pediatr Neurol 35: 303-307. 